\title{
Numerical and Experimental Study on Belleville Springs as Vibrational Element of Passive Vibration Assisted Rotary Drilling (pVARD) Tool for Drilling Performance Applications
}

\author{
Md. Shaheen Shaha, Dipesh Maharjan ${ }^{\mathrm{a}}$, Abdelsalam Abugharara ${ }^{\mathrm{a}, \mathrm{b}}$, Syed Imtiaz $^{\mathrm{a}}, \&$ Stephen Butt $^{\mathrm{a}}$

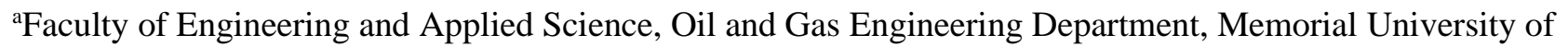 \\ Newfoundland, St. John's, NL, Canada
}

${ }^{b}$ Faculty of Engineering, Oil and Gas Engineering Department, University of Sebha, Libya

\begin{abstract}
A novel small-scale laboratory drilling tool, passive Vibration Assisted Rotary Drilling (pVARD) was previously designed and tested through intensive laboratory experiments in the Drilling Technology Laboratory at Memorial University of Newfoundland, Canada. The initial laboratory small-scale pVARD prototype showed promising results in enhancing drilling performance. The current laboratory drilling simulator (LDS) pVARD prototype is designed for wider-range drilling parameters of up to $100 \mathrm{kN}$ of applied Weight on Bit (WOB), $1200 \mathrm{~N}$-m of torque, and up to $1000 \mathrm{rpm}$ of rotational speed. For optimal pVARD configurations and best drilling results, a pVARD operational detail is an important step. The study of this paper concentrates on mechanically designing the pVARD compatible to the LDS, selecting optimal Belleville Springs, conducting experimental and simulation studies to optimize Belleville Springs stacking and pVARD configurations. The mechanical and simulation studies include conducting dynamic and static compression tests as well as a numerical study using simulation on various scenarios of Belleville Spring stacking. The initial mechanical compression tests, numerical study, and subsequent planned intensive drilling experiments can collectively provide important information in optimizing the pVARD fundamentals and can provide pVARD pre-setting and configurations based on the rock types to be drilled and the drilling parameters to be applied for the optimal drilling performance. The results of spring compression tests with the results of drilling performance (planned) can be analyzed based on drilling with and without pVARD. The results can also include the analysis of vibrations produced in both drilling systems recorded by an associated laser sensor.
\end{abstract}

Keywords-pVARD; Compression tests; Belleville Springs; Simulation; mechanical design; working load; drilling performance.

\section{INTRODUCTION}

A series of drilling experiments were carried out by the Drilling Technology Laboratory (DTL) using a small scale passive Vibration Assisted Rotation Drilling (pVARD) tool with a fully instrumented small-scale drilling simulator (SDS) fully described by Khorshidian et al., 2014 and Rana et al., $2015[1,2]$. The results of the previous studies (i.e. laboratory and numerical) using a small scale pVARD tool was productive and showed drilling performance enhancement through increasing the drilling Rate of Penetration (ROP). However, to further evaluate the operation mechanism of pVARD and how it can be optimally used to maximize drilling performance, a laboratory large scale pVARD is designed and tested and eventually utilized for laboratory drilling experiments using a fully instrumented large-scale drilling simulator (LDS) (Fig. 1).

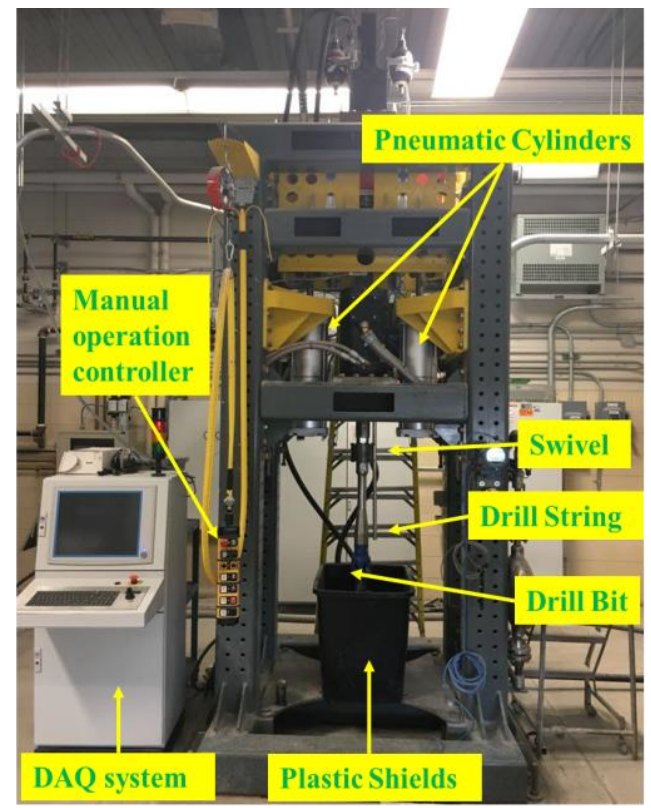

Figure 1. Laboratory Setup of the Large Drilling Simulator

Contact author:, mshaheens@mun.ca ${ }^{1}$,dmaharjan@mun.ca ${ }^{2}$, a_nasar@mun.ca ${ }^{3}$, simtiaz@mun.ca ${ }^{4}$, sdbutt@mun.ca ${ }^{5}$ 
The LDS-pVARD is manufactured to be attached to the drill bit during the experiment. This tool has been constructed using rock-bit interaction and induces axial vibration, providing full rotation speed and torque to the drill bit. This tool is comprised of three sections: (i) a compliant part of Belleville springs, which utilize induced axial vibrations, (ii) a dampening section of elastic materials (i.e. rubber), and (iii) a torque transmitting unit (Figure 2). Figure 2 also demonstrates the assembled pVARD including the inner shaft, the outer shell, and stacked rubber and springs. The inner blank shaft and the outer shell provides relative motion between the converse ends of the tool. Keys are used to transmit full torque to the drill bit. The compliance can be adjusted to different configurations in this tool by utilizing various spring stacking [2].

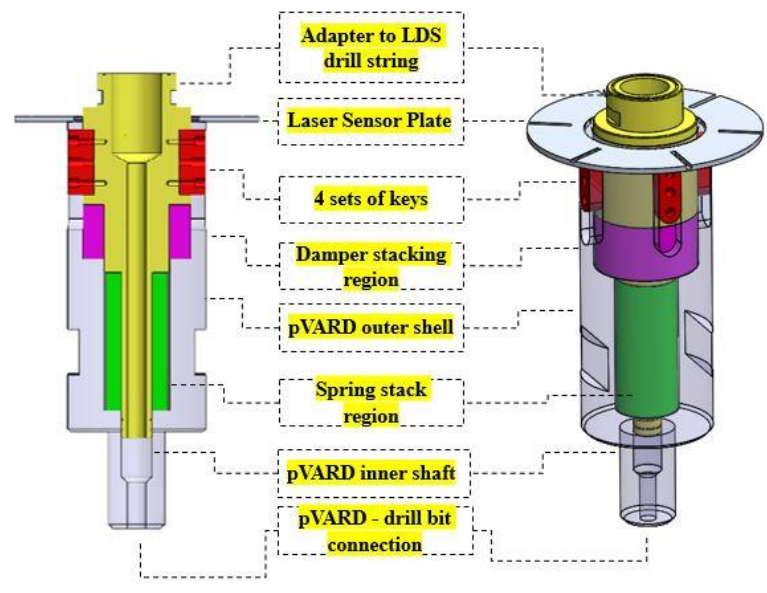

Figure 2. Longitudinal section (left), complete assembly (right) of pVARD

The dynamic simulation results of the LDS pVARD have been showed that adding a pVARD makes the drill string axially oscillate and compliant. These results are at lower system's natural frequency in the range of $100 \mathrm{rpm}$ to $600 \mathrm{rpm}$. Positive effects of the pVARD have been reported in this paper with specific conditions [7]. To determine the mechanism and the operational range of how the compliance of the pVARD works on the new drilling tool and how it can improve the rate of penetration in drilling by applying passive vibration, the authors invented a new testing method based on preceding vibration equipment that tests rubber and spring. Spring is the prime part of the pVARD tool and for this study the Belleville springs or coned disc springs are selected and tested in various stacking.

Belleville springs are generally exercised in different mechanical modes which can support various load statically or dynamically along its axis. This spring can be compressed and can generate different non-linear load-displacement curves by various standards. Although Julien Belleville patented the principle of the disc spring in 1867, it was published in 1936 [8,9]. Although several works have been done for Belleville Spring to better understand load-deflation graphs, Almen-Laszlo [10] first proposed it through a mathematical formula with some assumptions: the crosssection is assumed to be a small angular deviation, the spring cross-section does not pervert but only rotates at a neutral point, and the loads are centrally distributed. To improve the accuracy of this equation, several researchers have proposed theoretical models and approximate equations by revising the above-mentioned assumptions. Zhiming et al., 1990 [3] proposed and considered the finite rotation and greater discontinuity problems of the shell of a beam and an angular branch. Rosa et al., 2001 [4] has reported theoretical and numerical analysis on disc springs with linear variable thickness to extend the range of constant loads. When considering the effects of the calculation of friction for disc springs Curti et al., 1999 [5] proposed an analytical solution. Ozaki et al., 2012, [6] evaluated the outcomes of friction boundaries on the static and dynamic characteristic of the Belleville disc springs. However, in practice, the effect of the Belleville disk spring's friction factor cannot be measured, therefore some research is underway. In this study on Belleville disc springs the friction factor is ignored but its effect is identified through numerical and experimental comparative analysis.

This study is stage I in optimizing pVARD by performing numerous (numerical and experimental) compression tests involving different spring configurations that can lead to producing a spring compression details to be use in evaluating drilling performance against rigid drilling in stage II.

\section{II.PVARD COMPONENTS}

This section summarizes the basic characteristics of different components of LDS-pVARD tool. There are five major component groups including 1) Inner shaft, 2) Outer shell, 3) Keys, 4) Sensor plate, 5) Belleville Springs and Rubbers (Fig. 2). These parts are explained in more detail in the following sections:

\section{A. Inner Shaft}

The top of the inner shaft has a $13 \mathrm{~mm}$ through hole for circulating fluid and is designed to connect to the existing swivel of the LDS. There are four major turnings in the inner shaft which serves their unique purposes with a swivel connection, keys connection, rubber stacking and spring stacking. Moreover, the shaft section of the spring stacking also makes up a 1" space which is used for the O-rings (Fig. 2).

\section{B. Outer shell}

The outer shell of the pVARD is designed in such a way that it attaches to the inner shaft with the help of 4 keys while providing the movement of $32 \mathrm{~mm}$ towards the axis. The bottom of this shell is designed to connect to the rest of the drill string of the LDS. The top of the outer shell is turned 5 $\mathrm{mm}$ to place the sensor plate. In the inside, the outer shell has the landing faces for compression of springs and rubbers together with the sliding face for the O-rings (Fig. 2).

\section{Keys}

There are 4 keys that transmit torque between the inner and outer shaft. The keys have three holes. Two of these holes are in the top and bottom and do not have threads in them. These

Contact author:,mshaheens@mun.ca ${ }^{1}$, dmaharjan@mun.ca², a_nasar@mun.ca ${ }^{3}$,simtiaz@mun.ca ${ }^{4}$, sdbutt@mun.ca $^{5}$ 
holes are there to connect the keys to the inner shaft. The middle hole has thread in it and its purpose is to pop out the keys from the inner shaft while disassembling. All three holes are designed for the M5 $\times 1$ screws (Fig. 2).

\section{Sensor plate}

The laser sensor array reflector is a $5 \mathrm{~mm}$ thick aluminum plate with 6 uniformly spaced grooves as shown in Figure 2. Five grooves have a cross-section of $5 \mathrm{~mm}$ (width) $\times 3.5 \mathrm{~mm}$ (depth) and the sixth groove has a cross-section of $5 \mathrm{~mm}$ (width) $\times 1.5 \mathrm{~mm}$ (depth). The unique depth of sixth groove is to identify the completion of one rotation during the analysis of the laser sensor data used to measure several parameters such as the level of axial vibrations, rotational speed, etc.

\section{E. Belleville Springs and Rubbers}

The LDS- pVARD is designed for 1" ID and 2" OD of Belleville springs. The rationale behind the selection of this Belleville spring dimension is the availability of 4 different springs with unique compliances that share the same dimensions (ID and OD). This makes it applicable to change the compliance of the tool itself not only by changing the spring configuration but also by using a completely different spring type, thus adjusting the range of the pVARD working range. The height of the spring stack is designed to be 5 ", in an experimental scenario where total spring height is less than 5 ", the remaining space must be filled with rigid spacers.

Likewise, each rubber ring is designed with 2.35" ID, 3.70" OD, and 0.25" thick as shown in Figure 2. Four sets of these rubbers are stacked in series when assembling the tool. Since these rubbers are not used as perfect dampers, they possess certain amount of spring elements along with the damper element. For accurate estimation of the tool compliance, the damping coefficient and the spring coefficient of the rubbers must be experimentally calibrated and integrated into the numerical modeling of the tool.

\section{III.FINITE ELEMENT ANALYSIS}

This section presents the results of the Finite Element Analysis (FEA) of the torque transmitting section of the LDSpVARD. For the simplicity of the simulation, all the complex features like thread, chamfers, through holes (in the inner shaft), etc. of the components are suppressed. Table 1 summarizes the configurations of the simulation.

Table 1. Summary of configuration settings for FEA

\begin{tabular}{|c|c|}
\hline Particular & Description \\
\hline Components & Keys, inner shaft \& outer shell \\
\hline Material & AISI 4140 Steel \\
\hline Tensile Strength $\left(\sigma_{t}\right)$ & $655 \mathrm{MPa}$ \\
\hline Yield Strength $\left(Y_{s}\right)$ & $415 \mathrm{MPa}$ \\
\hline
\end{tabular}

\begin{tabular}{|c|c|}
\hline Young's Modulus $(E)$ & $200 \mathrm{GPa}$ \\
\hline Meshing & Curvature-based mesh \\
\hline Mesh quality & High \\
\hline $\begin{array}{c}\text { Minimum element } \\
\text { size }\end{array}$ & $10 \mathrm{~mm}$ \\
\hline $\begin{array}{c}\text { Maximum element } \\
\text { size }\end{array}$ & $1200 \mathrm{Nm}$ \\
\hline Torque & \\
\hline
\end{tabular}

\section{A. Results of Simulation}

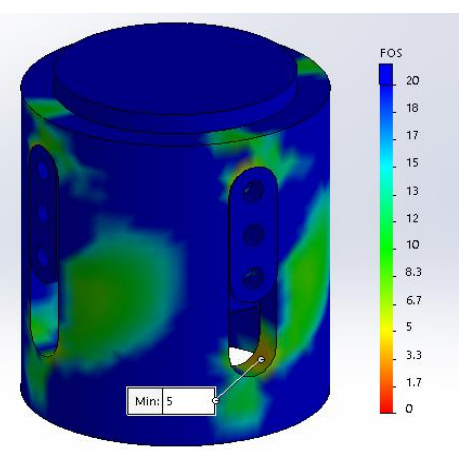

Figure 3. Showing minimum FOS in the Outer shell

The simulation results provided in this section are interpreted in terms of the minimum factor of safety (FOS), which is related to the maximum stress concentration. The results of the FEA analysis show that the keys can safely transmit the torque of $1200 \mathrm{Nm}$ with an FOS of more than 10. As shown in Figure. 3, the highest concentration in the keys occurs at the through holes of the screws.

Similarly, the outer shell has a minimum FOS of 5 at the far end of the slots where the keys are engaged and the maximum stress concentration in the inner shaft occurs at the top and bottom contact points. The keys have an average FOS of 16, where both FOS are assumed to be satisfactory for this design.

\section{EXPERIMENTAL APPARATUS}

\section{A. Mechanical compression tests:}

A mechanical compression test is conducted to measure the specimen's (Belleville springs) properties by applying compressive loading in the opposite direction, as opposed to squeezing or flattening. The tested specimen is usually placed between two plates, with the load being distributed across the entire surface of the two opposite faces of the sample. Then, the plates are advances towards one another by a standard test machine to flatten the sample. Typically, a compressed sample is shortened by the applied force and extended axially.

Contact author:,mshaheens@mun.ca ${ }^{1}$, dmaharjan@mun.ca², a_nasar@mun.ca ${ }^{3}$, simtiaz@mun.ca ${ }^{4}$, sdbutt@mun.ca $^{5}$ 
The compression test, which is the opposite of the more general tension test [11], is performed to determine the behavior or the response of the material by sensing a compressive load and measuring the basic variables such as strain, stress, and deformation. During the experiment, different properties of the specimen are recorded, calculated, and plotted as a stress-strain diagram that is used to measure the properties of elastic limit, proportional limit, yield point, yield strength, and compressive strength for some materials $[5,13,15,16]$.

The three main compression tests were conducted on two different stacking of Belleville springs that include 10 and 18 sets of the model $9712 \mathrm{k} 31$. There are 18 numbers associated with the Belleville coned disc springs. The loading range of

$$
\begin{aligned}
& F=\frac{4 \cdot E}{\left(1-\mu^{2}\right)} * \frac{t^{3} \cdot s}{K_{1} \cdot D_{e}^{2}}\left[\left(\frac{h_{o}}{t}-\frac{s}{t}\right) \cdot\left(\frac{h_{o}}{t}-\frac{s}{2 t}\right)+1\right] \ldots \ldots \ldots .2 \\
& K_{1}=\frac{1}{\pi} \cdot\left[\frac{\left(\frac{\delta-1}{\delta}\right)^{2}}{\left(\frac{\delta+1}{\delta-1}-\frac{2}{\ln \delta}\right)}\right] \\
& \delta=\frac{D_{e}}{D_{i}}
\end{aligned}
$$

The coned disc springs used in this analysis have the following material properties: (i)Young's modulus $E=210$ $\mathrm{GPa}$ and (ii) Poisson's ratio $\mu=0.3$. This calculation is designed for a Belleville spring without any machine assistance. Furthermore, the calculation does not take into account the effect of friction. The purpose of this analysis is

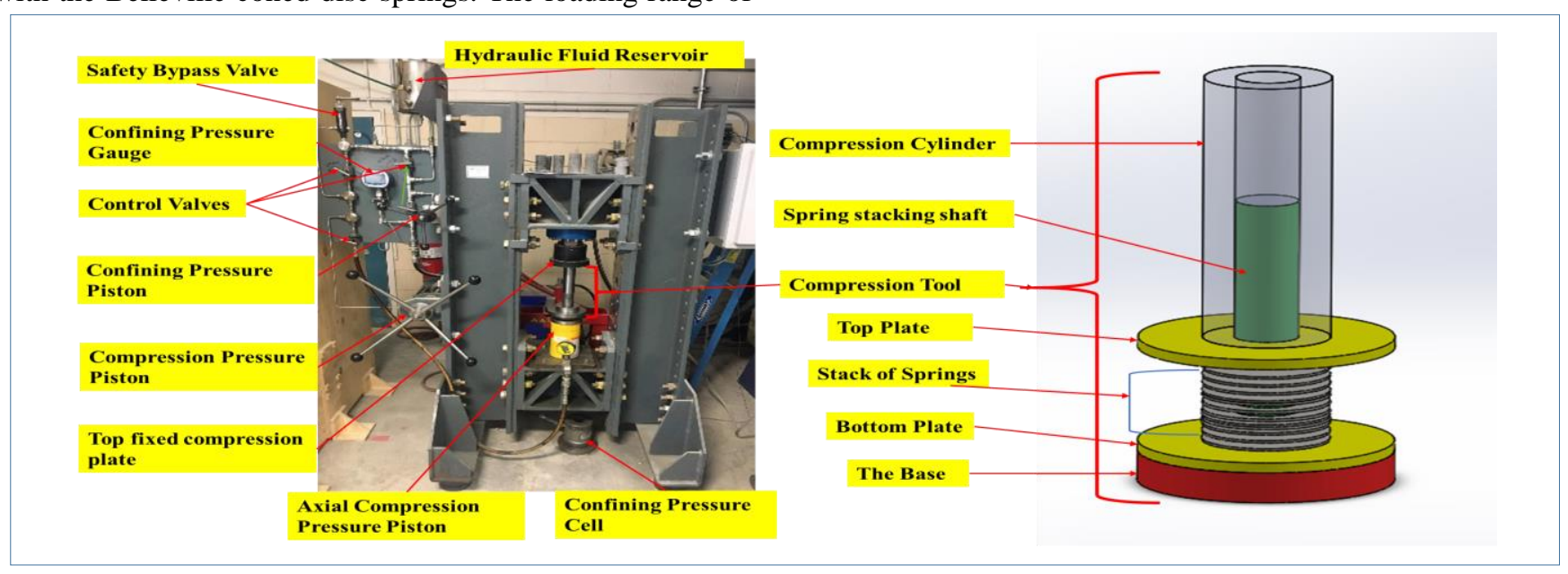

Figure 4. Geomechanics loading frame and pVARD spring compression tool

this test is selected with the average $22 \mathrm{kN}$. The spring compression details are determined using Hooke's law (1960) which derives the relationship between the compressive load and the deflection with stiffness. In this experiment, the load frame is set up at different loading rates and resulted in displacement. Stiffness is obtained from Hooke's formula [12].

$$
F=-K x \ldots \ldots \ldots \ldots \ldots \ldots \ldots \ldots .1
$$

Here, $\mathrm{F}$ is the restoring force, $\mathrm{x}$ is the displacement from equilibrium or deformation, and $\mathrm{k}$ is a constant related to the difficulty in deforming the system called displacement. The minus sign indicates that the restoring force is in the direction opposite to the displacement.

\section{B. Simulation :}

The numerical study has been done by simulation. This simulation is programmed based on the Almen and Laszlo, 1936 equation $[10,15,17]$. This equation derives the relationship between spring force " $F$ " and spring deflection of a coned disc spring having thickness of " $\mathrm{t}$ ", inner radius of " $D_{i}$ ", outer radius of" $D_{e}$ ", disc height of " $h$ ", inside disc height of " $h_{0}(h-t)$ ", dimension ratio of " $\delta$ " and shape coefficient of " $K_{1}$ " which is described in Equation 2. compatible for large loading forces, characteristics of nonlinear (degressive) work, measuring spring constant (stiffness), less space requirements, simple mounting and dismantling, less production costs, etc. For this analysis, there are some parameters of spring specification data involving the outer/inside diameter, minimum/maximum working load, working stroke, disc height, and material thickness, which all can be provided by the manufacturer. The simulation produces the maximum permissible loading with maximum spring deflection. By obtaining this data spring stiffness is calculated by using Hooke's formula equation 1. In addition, more analysis can be performed by Microsoft Excel using the same spring specification without any simulation. The conclusive comments have come after completing data processing from the simulation and Microsoft Excel [15, 17].

\section{V.EXPERIMENTAL PROCEDURE AND METHODOLOGY}

The Experiments were conducted using the compression tool set described in Figure 4 (right). 


\section{VI.RESULTS AND DISCUSSION}

The numerical and experimental analysis were conducted, and the results are discussed sequentially. With the help of the simulation, the characteristics of $1-10 \&$ \& $1-18$ configurations of the $9712 \mathrm{k} 31$ springs were analyzed. A load vs. displacement relationship is drawn using the simulation results of 1-10 configurations of the $9712 \mathrm{k} 31$ as shown in Figure 5. In this figure the resulted trend is liner.

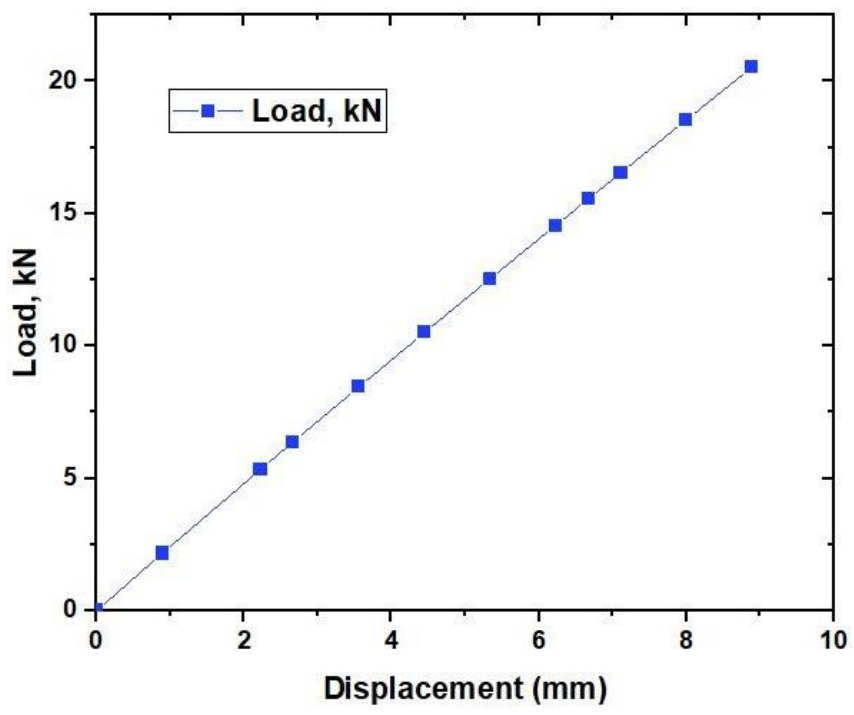

Figure.5-Simulated result of "1-10, 9712k31" spring configuration

Also, a load vs. displacement relationship is drawn using the simulation results of $1-18$ configurations of the "9712k31" spring is shown in Figure 6. In this figure the resulted trend is liner applying the same force, however the complete flattening occurs at longer displacement.

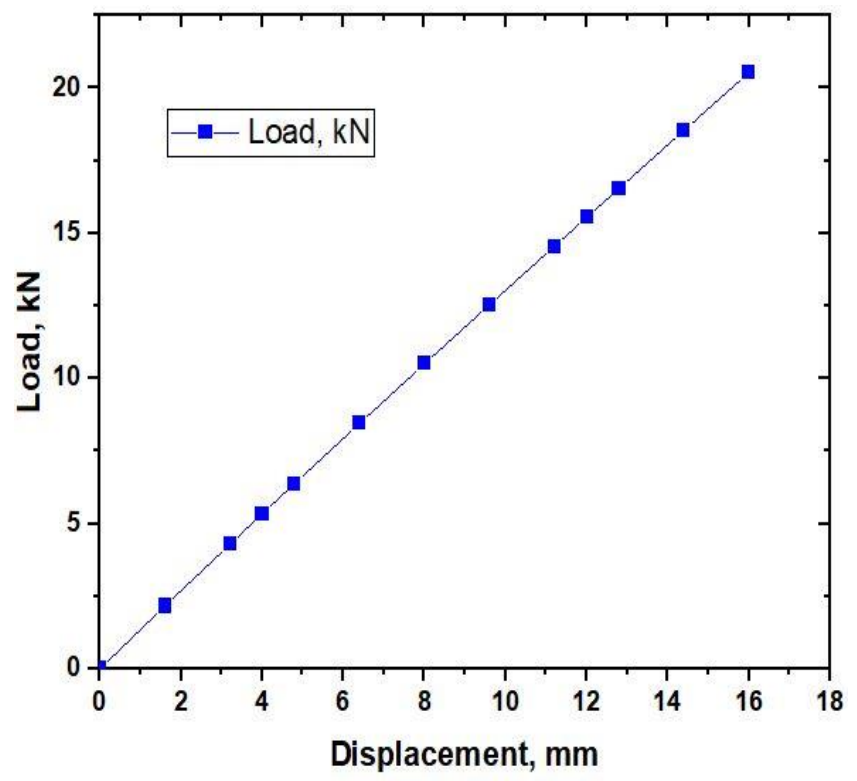

Figure 6. Simulated result of " $1-18,9712 \mathrm{k} 31$ " spring configuration
In compression test was repeated three times $(\mathrm{a}, \mathrm{b}, \mathrm{c})$ on both spring configurations of the [ 10 series in a single parallel configuration of the $9712 \mathrm{k} 31]$ and the [18 series in a single parallel configuration of the 9712k31]. The results of these repeated tests are displayed in Figure 7 and Figure 8, respectively. All results show liner relationships.

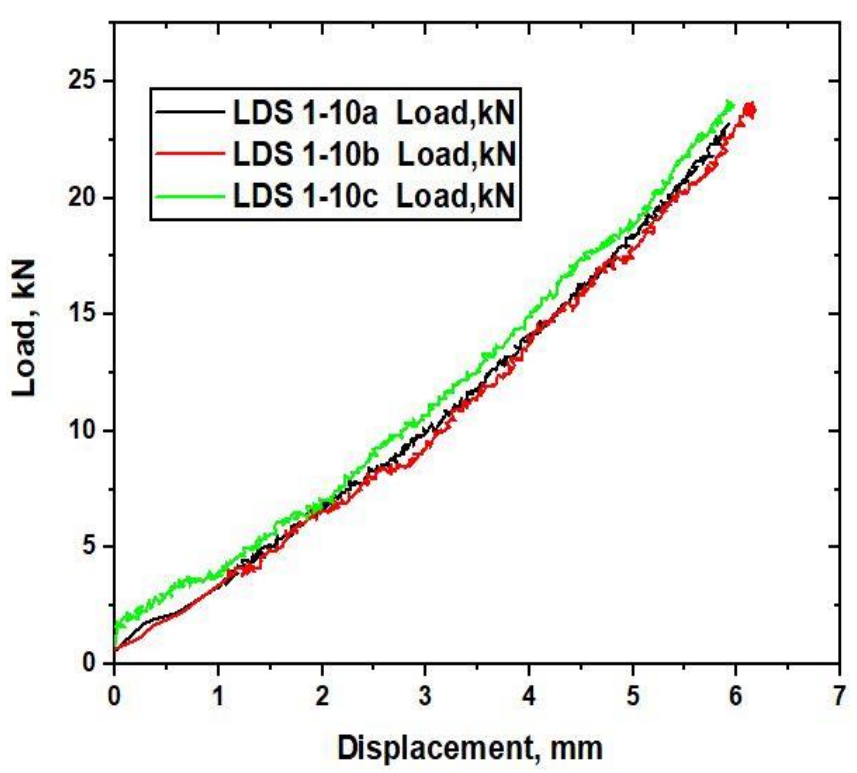

Figure 7. Three compression test results of the of " $1-10$; $9712 \mathrm{k} 31$ " spring configuration.

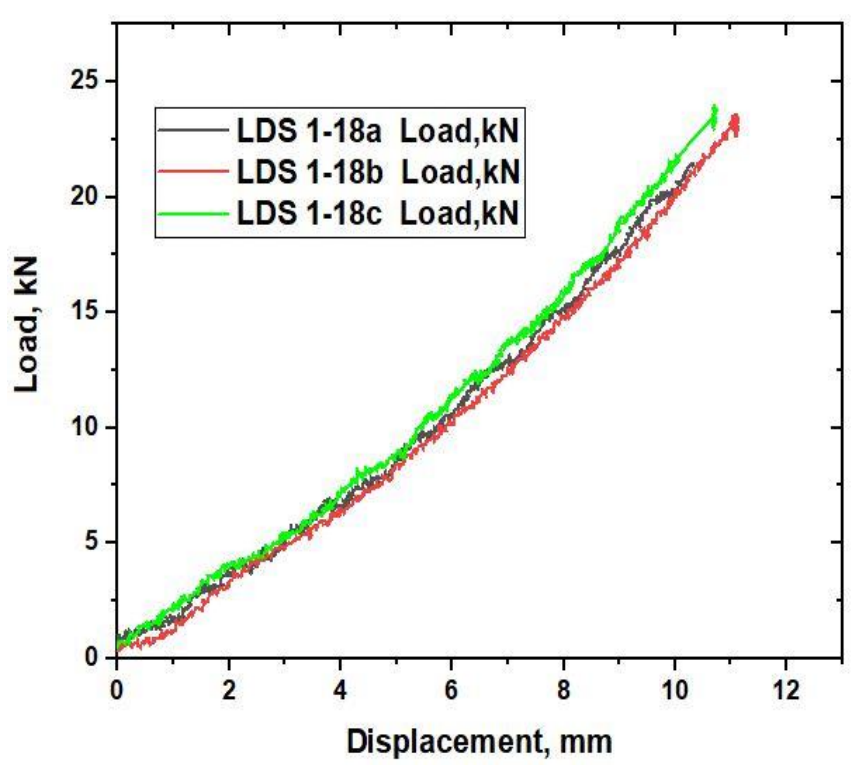

Figure 8 . Three compression test results of the "1-18,9712k31" spring configuration.

A comparative analysis of both (i) simulation and (ii) the mechanical compression test performed on $9712 \mathrm{k} 31$ spring type is displayed in Figures 9 and 10. The simulation does not consider the friction factor but there is a friction factor considered in the compression test. Due to the increase of the contact area between the compressed springs with the

Contact author:,mshaheens@mun.ca ${ }^{1}$,dmaharjan@mun.ca², a_nasar@mun.ca ${ }^{3}$, simtiaz@mun.ca ${ }^{4}$, sdbutt@mun.ca $^{5}$ 
increasing load, the friction increases and the resistance of spring flattening increases, which influences the curve of the mechanical tests to deviate upwards. This can be observed in Figures 9 and 10.

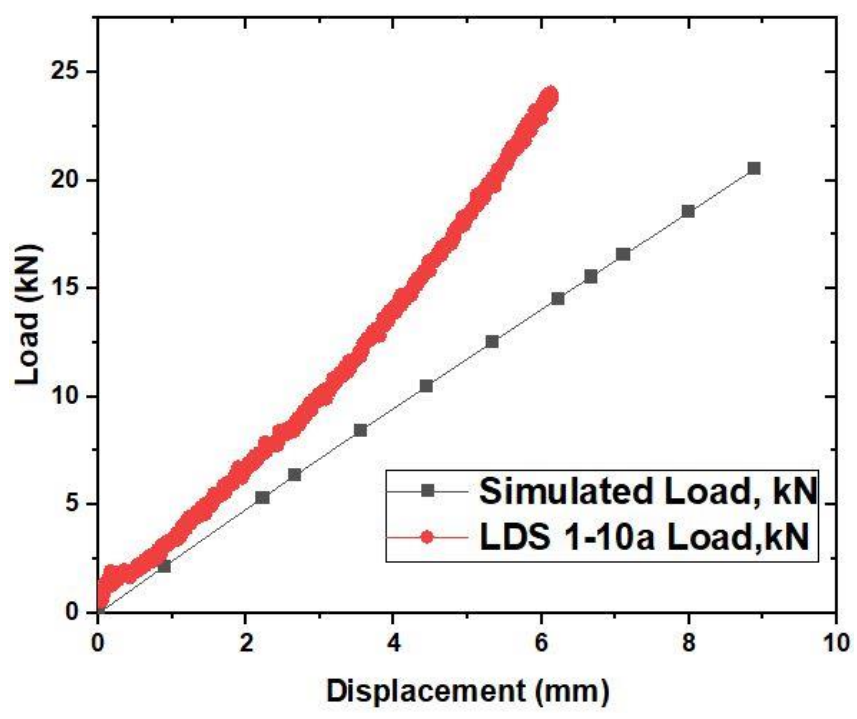

Figure 9. Comparison of the simulation with compression test result of the "1-10,9712k31" spring

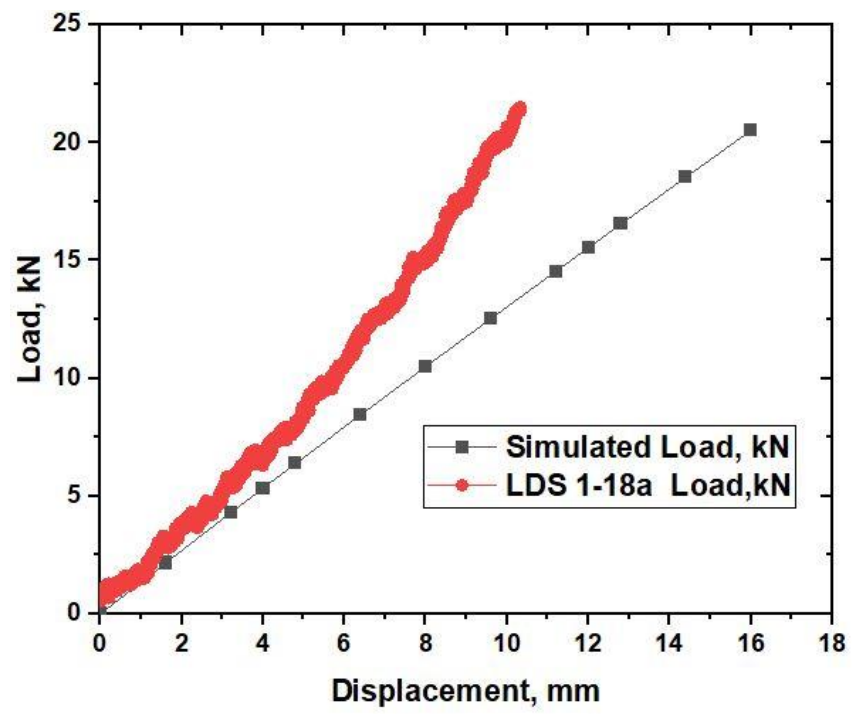

Figure 10. Comparison of the simulation with compression test result of the "1-18,9712k31" spring

\section{VII.RECOMMENDATIONS}

This paper proposes a new simplified mechanical analysis with simulation results to emulate the force-displacement relationship of Belleville springs as a vibrational element of LDS-pVARD. For simulation, this calculation is designed for Belleville springs without machined contact surfaces. Furthermore, the calculation does not consider the effect of friction, whose effect is noticed in compression results in Figures 9 and 10. But for the mechanical testing, the friction factor is dominant and increases with the increase of the contact area between the springs as the load increases.

The annular ring of the empty trimmed cone can be able to absorb external axial forces counteracting against each other. The spring section is generally rectangular. Large size springs $(\mathrm{t}>6 \mathrm{~mm})$ are made with machined contact flats. Belleville springs are laid out for higher loads of low displacements that are used individually or in sets. While using springs in a set, the effects of friction need to be considered. The set contains 3 - 5\% loading per friction level therefore the working load must be increased. The working load must then be increased forcefully $[15,17]$.

From Figures 9 and 10, the theory of the effect of the friction factor is approved. Frictional losses in the springs are dependent on the type of spring stacking. When the number of springs stacked in parallel is less, edge friction accounts for most of the frictional loss. In addition, there is friction loss due to geo-mechanics loading frame operations with the springs. Similarly, as observed from figures 9 and 10, frictional loss is also dependent on the spring load or spring deflection. For the high load and standard Belleville springs, frictional loss increases proportionally with spring deflection. So, if the friction factor can be calibrated, then the accuracy of this approach goes toward improving or validating its accuracy. Therefore, how to control friction loss should be examined in future research.

\section{VIII.CONCLUSION}

The results from the simulation show that the design parameters of the LDS-pVARD tool fulfill the safety requirements with minimum FOS of 5.

The scope of this work is limited to the mechanical design and static analysis of the LDS-pVARD tool. It does not include the tasks related to the fatigue analysis, the design of experiment, selection of the spring stacking and/or the calibration of tool compliance, which will be considered in future research. However, some mechanical compression tests on various scenarios of spring stacking have been conducted and analyzed in this paper. Fatigue analysis of pVARD as well as drillstring components will be involved in future studies.

The comparative analysis of the compression results of pVARD springs obtained from Geo-mechanics loading frame and the simulation demonstrated the need for determining the friction factor. Such friction factor is key to producing the pVARD fundamentals and therefore, make drilling data (planned) more representative.

\section{REFERENCES}

[1] Khorshidian, H., Butt, S. D. and Arvani, F, "Influence of High Velocity Jet on Drilling Performance of PDC bit under Pressurized Condition". American Rock Mechanics Association 2015, the 48 ${ }^{\text {th }}$ US Rock Mechanics/GeoMechanics Symposium, Minneapolis, MN, USA.

[2] Rana, P.S, A.N. Abugharara, S.D. Butt and J. Molgaard, "Experimental and Field Application of Passive-Vibration Assisted Rotary Drilling (pVARD) Tool to Enhance Drilling Performance.” American Rock

Contact author:,mshaheens@mun.ca ${ }^{1}$, dmaharjan@mun.ca², a_nasar@mun.ca ${ }^{3}$,simtiaz@mun.ca ${ }^{4}$, sdbutt@mun.ca $^{5}$ 
Mechanics Association (ARMA-2015), the $49^{\text {th }}$ US Rock Mechanics / Geomechanics Symposium, San Francisco, CA, USA.

[3] Y. Zhiming,Y. Kaiyuan, ".A study of belleville spring and diaphragm spring in engineering". Journal of Applied Mechanics, ASME, 1990, vol. 57, no. 4, pp. 1026-1031.

[4] G. La Rosa, M. Messina, and A. Risitano, "Stiffness of variable thickness belleville springs," Journal of Mechanical Design, ASME, 2001, vol. 123, no. 2, pp. 294-299.

[5] G. Curti, R. Montanini, " On the influence of friction in the calculation of conical disk springs". Journal of Mechanical Design, ASME, 1999,vol. 121, no. 4, pp. 622-627.

[6] S. Ozaki, K. Tsuda, J. Tominaga, “ Analyses of static and dynamic behavior of coned disk springs: Effects of friction boundaries". ThinWalled Structure, 2012, vol. 59, pp. 132-143.

[7] D. Maharjan, J. M. Junior, G. Rideout, S. Butt "Bond graph analysis of p-VARD” Progress in Canadian Mechanical Engineering, 2020.

[8] J. Shigley, C. Mischke,T. Brown, Standard Handbook of Machine Design. McGraw- Hill Standard Handbooks, 2004.

[9] N.L. Pedersen, P. Pedersen, "Stiffness and design for strength of trapezoidal Belleville springs". .The Journal of Strain Analysis for Engineering Design, 2011,vol.46.

[10] J. O. Almen, A. Laszlo, "The uniform-section disk spring". Transactions of the American Society of Mechanical Engineers,1936, 1990, vol. 58, pp. 305-14.

[11] M. H. Hamidon, M.T.H., Sultan, A.H., Ariffin, "Investigation of mechanical testing on hybrid composite materials". Failure Analysis in Biocomposites, Fibre-Reinforced Composites and Hybrid Composites, 1st ed ,Woodhead Publishing Series in Composites Science and Engineering, 2019.

[12] M. J.Giuliodori, H. L Lujan, W. S. Briggs, G. Palani, S.E. DiCarlo, "Hooke's law: applications of a recurring principle". The Journal of Advances in Physiology Education, 2009, vol 33,pp. 293-296.

[13] M. Paredes, "Analytical and Experimental Study of Conical Telescoping Springs with Non-Constant Pitch", Journal of Mechanical Design,2013, vol.135, no.9, pp.1-8.

[14] www.instron.us/ [Accessed on February 19,2020]

[15] Schnorr, "Handbook for Disc Springs.”, Schnorr Corporation Ann Arbor, MI, 2003.

[16] www.testresources.net/ [Accessed on February 19,2020]

[17] M. Paredes, "Methodology to build an assistance tool dedicated to preliminary design: application to compression springs". International Journal on Interactive Design and Manufacturing, 2009, DOI 10.1007/s12008-009-0079-3.

Contact author:,mshaheens@mun.ca ${ }^{1}$, dmaharjan@mun.ca², a_nasar@mun.ca ${ }^{3}$,simtiaz@mun.ca ${ }^{4}$, sdbutt@mun.ca $^{5}$ 